\title{
DiCOTOMÍAS DOCUMENTADAS: LAS OBRAS DE KSENIIA KHRABRYKH COMO LA VENTANA HACIA LA OTREDAD
}

\section{Documented dichotomies: the works of Kseniia Khrabrykh as a window towards Otherness}

\author{
Anna BORISOVA \\ Personal Investigador en Formación \\ Universidad de Murcia, España \\ E-mail: anna.borisova@um.es \\ (iD) https://orcid.org/0000-0002-3740-9622
}

Fecha de recepción del artículo: 29/03/2019

Fecha de aceptación definitiva: 18/04/2019

\begin{abstract}
RESUMEN
Las dicotomías conceptuales "masculino-femenino", "Yo-Otro" estructuran nuestra realidad, fomentando desigualdades y dejando fuera de consideración cualquier fenómeno híbrido. En el presente ensayo analizamos los recursos expresivos que se emplean en los documentales 'Art of Being Yourself', 'The Word' y 'Vidimo-Nevidimo' de Kseniia Khrabrykh, una artista rusa emergente que pretende desafiar los esquemas cognitivos dicotómicos, crear un espacio simbólico de encuentro con la Otredad y promover así las actitudes empáticas y tolerantes hacia la diversidad inherente a la sociedad actual. Partimos de la aproximación a las diferentes perspectivas teóricas sobre el papel de alteridad en la construcción identitaria (incluyendo los feminismos postcoloniales y los estudios queer) para luego corroborar la presencia de sus principios en los tres proyectos mencionados. Seguidamente, nos centramos en definir el discurso conceptual de cada obra, el formato de su narrativa visual, su manera de evocar la problemática tratada y el nivel de la interactividad del trabajo.
\end{abstract}

Palabras clave: narrativa audiovisual documental; otredad; dicotomías; feminismo postcolonial; teoría queer.

\begin{abstract}
The conceptual dichotomies "masculine-feminine», "Self-Other» structure our reality by leaving out any hybrid phenomenon and, therefore, foment inequalities. In the present essay we analyse the expressive strategies that are used in the documentaries 'Art of Being Yourself', 'The Word' and 'Vidimo-Nevidimo' by Kseniia Khrabrykh, an emerging Russian artist who challenges the dichotomous cognitive schemes, creates a symbolic space of encounter with Otherness and thus promotes empathetic and tolerant attitudes towards the inherent social diversity. We start by approaching the theories on the role of alterity in the construction of identity (including perspectives of postcolonial feminisms and queer studies) with the aim to corroborate the presence of its principles in the three mentioned
\end{abstract}


projects. Next, we focus on defining the conceptual discourse of each work, the format of its visual narrative, its way of evoking the problems treated and the level of its interactivity.

Key words: documentary audiovisual narrative; otherness; dichotomies; postcolonial feminism; queer theory.

\section{INTRODUCCIÓN}

La mente humana tiende a crear dicotomías conceptuales como modo de estructurar la realidad: el bien y el mal, el cielo y la tierra, lo verdadero y lo falso, el hombre y la mujer, el amigo y el enemigo, el Yo y el Otro. Esta división clara y aparentemente irrefutable proporciona una cierta seguridad, ya que sirve de punto de anclaje para valorar las experiencias y las relaciones que surgen en la interacción con el mundo circundante. Nos autodefinimos en contraposición a algo que consideramos extranjero a nosotros: pertenecemos a este género y no a otro, somos de esta nacionalidad y no de otra, etc. No obstante, este mecanismo de lucha contra la incertidumbre existencial no es tan inocente como parece a primera vista, ya que deja fuera de consideración la presencia de distintas hibridaciones entre las nociones determinadas como dicotómicas.

La rigidez de los planteamientos estancos frecuentemente acarrea conflictos, cuando surgen fenómenos que no se encuadran de manera clara en ninguna de las verdades establecidas y se quedan en los márgenes del sistema impuesto a la espera de que alguien se atreve a nombrar lo innombrable. Las contrariedades presuponen el miedo hacia lo opuesto, pero más aún hacia lo desconocido y lo no calificable. En este sentido, para promover las actitudes tolerantes hacia la diversidad social, es necesario reconocer la existencia de los fenómenos híbridos y la utopía de las verdades absolutas, pero este cambio de perspectiva resulta imposible sin una inmersión temporal en la realidad del Otro. Al hilo de ello, el pensamiento feminista postcolonial y la teoría queer proponen romper con los paradigmas identitarios esencialistas e introducir nuevas representaciones en el imaginario colectivo que aludan a la flexibilidad, la pluralidad y el diálogo. Sus planteamientos encuentran reflejo en las prácticas videográficas documentales de carácter subversivo.

Para ilustrar esta tendencia en el presente estudio nos centraremos en las obras audiovisuales 'Art of Being Yourself' (2012), 'The Word' (2017) y 'Vidimo-Nevidimo' (2018) de la artista rusa emergente Kseniia Khrabrykh. En estas piezas la documentalista trata de visibilizar la injusticia oculta en los esquemas dicotómicos de la interpretación de la realidad que deriva en la discriminación de las personas que encarnan a la Otredad. Con este fin ella utiliza distintos recursos visuales, narrativos e interactivos. Analizaremos los discursos de los proyectos documentales mencionados para determinar las estrategias que emplea cada uno de ellos para ofrecer un encuentro con la alteridad. Para cumplir este objetivo, primeramente, profundizaremos en distintas teorías acerca de la construcción del self y sus concepciones del papel del Otro en este proceso. En este sentido, nos centraremos en las perspectivas propuestas por el pensamiento feminista y queer y en las representaciones videográficas vinculadas a este tema. Seguidamente, estudiaremos las tres obras que versan sobre las consecuencias de la inaceptación de las diferencias: definiremos su enfoque conceptual, su formato de la construcción del relato visual, su manera de evocar la problemática tratada, el nivel de la interactividad del trabajo, etc. De este modo, observaremos la evolución del 
discurso artístico subversivo de la artista rusa emergente que trata de lograr un cambio en los paradigmas sociales dicotómicas en su país.

\section{Metodología}

La presente investigación exige un tratamiento metodológico interdisciplinar, ya que implica manejar los conceptos propios de distintas áreas del saber: la filosofía, la psicología, la comunicación audiovisual, el arte, etc. En primer lugar, los planteamientos filosóficos, psicológicos, feministas y queer acerca de la construcción identitaria nos ayudan a trazar las distintas articulaciones teóricas que atañen las nociones del Yo y del Otro y entender su influencia en el nivel de la aceptación social de la diferencia. En segundo lugar, profundizamos en las tendencias postcoloniales del pensamiento feminista y los estudios queer para esbozar su perspectiva y sus propuestas de representación de la Otredad. A continuación, nos adentramos en el universo artístico de Kseniia Khrabrykh, una creadora interdisciplinar que opera desde San Petersburgo (Rusia), para estudiar sus tres obras documentales siguiendo el método interpretativo en su dimensión semiótica (Zavala, 2010). En este sentido, nos centramos en el enunciado de la pieza audiovisual y su estructura, más que en sus aspectos estéticos. Tratamos de determinar los patrones de uso de los recursos artísticos en los trabajos mencionados y su papel en la desvirtuación del pensamiento dicotómico.

Accedimos a las producciones citadas a través de la página web del Taller del Arte Interactivo, un proyecto de la artista, cuyo objetivo es promover las prácticas artísticas interactivas en el contexto de Rusia. Es importante mencionar que no todas las obras seleccionadas para el estudio actualmente están disponibles online, aunque la descripción de las propuestas creativas aparezca en la lista de los trabajos recientes de la artista. Es el caso del documental interactivo 'The Word', cuya página web está temporalmente suspendida debido a los desarreglos de carácter legal entre la autora y la entidad que financió el proyecto.

\section{Planteamientos teóricos}

\subsection{El concepto de Otredad}

Frecuentemente, no nos damos cuenta del modo en que los esquemas dicotómicos del pensamiento, arraigados en nuestra mente, cambian nuestra percepción del mundo. En este sentido, a veces el concepto de la identidad se concibe como antagónico de la Otredad. Estoy Yo y todo lo que me es familiar y conocido, lo que me ha influido para ser lo que soy, y está lo Otro, todo lo demás, que desconozco e, incluso, temo. Al hilo de ello, Stuart Hall insiste en que el proceso de la autodefinición se lleva a cabo desde la diferencia, estableciendo las fronteras simbólicas entre los dominios del self y la alteridad, y, en consecuencia, «necesita lo que queda afuera, su exterior constitutivo, para consolidar el proceso" (Hall, 2003, p. 16). Pero la percepción de la Otredad vista desde la perspectiva de lo que uno no es, depende en gran medida del enfoque atribuido a la identidad. En el caso de que la entendamos como algo inamovible, todo ajeno a ella se convierte en un peligro para su integridad. Por lo contrario, si aceptamos que nuestro Yo se transforma constantemente bajo la influencia del entorno, lo Otro se torna un impulso para la evolución. Este segundo planteamiento 
se encuadra dentro de la teoría constructivista de la subjetivación, la que actualmente está cobrando cada vez más fuerza, ya que se ajusta mejor a la realidad del mundo actual cambiante. Hall (2003) asume los postulados constructivistas acerca de la identidad y, por tanto, presenta la Otredad como condición indispensable para la conformación del discurso identitario, pero la ve como una fuerza externa al individuo.

Otra manera de enfocar esta cuestión propone Leonor Arfuch (2002). Esta autora afirma que los discursos identitarios se construyen como el resultado de un intercambio simbólico con un interlocutor interno. Para fundamentar su argumentación ella recupera la teoría de dialogismo de Mikhail Bajtín que incide en el papel esencial del Otro en el diálogo interior y remarca que los enunciados dirigidos a describir nuestra subjetividad se formulan en relación a él. Por consiguiente, es una presencia simbólica constante que influye en cómo nos percibimos a nosotros mismos y cómo nos situamos en el mundo. De esta manera, la identidad integra la alteridad, forman entre ellas un "nosotros", no sólo porque el individuo toma de referencia la segunda para conformar y verificar la primera, sino también porque un discurso sin interlocutor pierde todo sentido. Así, según esta línea de pensamiento, para conocernos a nosotros mismos y comprender al Otro debemos aceptar la importancia de lo ajeno y lo desconocido como parte inherente a nuestro self en constante reconstrucción. Julia Kristeva (1991) en su libro 'Extranjeros para nosotros mismos' se adscribe a estos postulados y alienta a reconocer la interrelación positiva entre el Yo y el Otro para asumir la diversidad como parte de nuestras sociedades y así evitar los conflictos por falta de la tolerancia:

[...] tal vez a partir de la subversión de este individualismo moderno, a partir del momento en que el ciudadano-individuo deja de considerarse unido y glorioso, y descubre sus incoherencias y sus abismos -sus "extranjerías", en suma-, cuando la cuestión se plantea de nuevo: fin de la acogida del extranjero en el interior de un sistema que lo anula para dar paso a la cohabitación de los extranjeros que todos reconocemos ser (Kristeva, 1991, p. 10).

Aquí la autora hace referencia al concepto de «inquietante extranjería» propuesto por Sigmund Freud para señalar nuestros miedos ante lo desconocido como el origen de nuestro rechazo a todo lo que representa la Otredad. Solo el esfuerzo por dialogar, empatizar y comprender a quién es diferente es capaz de vencer esta reacción negativa ante la incertidumbre que genera el encuentro con él.

Puede parecer que el concepto de Otro en los discursos de los autores mencionados se refiere sobre todo a las personas pertenecientes a las culturas diferentes a la nuestra, a los contextos geográficos fuera de nuestra zona de confort. No obstante, se trata de una noción que abarca un territorio simbólico mucho más amplio, creado en cierta medida por los esquemas dicotómicos de organización social. Así, entre las categorías opuestas que delimitan las fronteras de la Otredad se encuentran: lo femenino frente a lo masculino, la enfermedad frente a la salud, la pobreza frente al bienestar, la homosexualidad frente a la heterosexualidad, el inmigrante frente al autóctono, las minorías (étnicas, raciales, sexuales, etc.) frente al grupo dominante. Como afirma Olsen (2009), estas dualidades no se conciben en términos de igualdad, sino que son conceptos jerarquizados, uno siempre es inferior al otro. El pensamiento postcolonial y los estudios queer cuestionan este modelo dicotómico del mundo, lo tachan de limitado y opresivo y ofrecen alternativas en el marco de sus actuaciones subversivas, incluidas las prácticas vinculadas a la producción audiovisual documental. 


\subsection{La Otredad en los discursos feministas postcoloniales y en la teoría queer}

A mediados del siglo XX Simone de Beauvoir formuló la teoría acerca de la Otredad femenina como construcción sociocultural patriarcal. A diferencia de los demás constructos dicotómicos, la autora definía la dualidad «hombre - mujer» como universal (de Beauvoir, 2013). Además, era irreversible, lo que significaba que la alteridad del varón no se contemplaba nunca y, por lo contrario, siempre acompañaba a la mujer:

por ejemplo, si para un pueblo los otros son los «extranjeros", para esos «extranjeros", los otros serán quienes les llaman así. Es decir, el sentimiento de los otros es recíproco. Con la mujer no ocurre eso. El hombre en ningún caso es el otro (Varela, 2005, p. 84).

Este planteamiento corresponde a una perspectiva esencialista del proceso de subjetivación y, bajo el avance de las teorías constructivistas, queda desfasado (Cano, 2016). En estas últimas, como ya hemos mencionado antes, la identidad se presenta como un concepto que hace referencia a un Yo flexible, dinámico y multidimensional, en constante transformación bajo la influencia del entorno. Al hilo de ello, Marián López Fernández (1991) remarca que en la posmodernidad el sujeto tradicional se disuelve debido a "la desaparición del sentido de la historia» (p.103). El relato colectivo que antes articulaba las experiencias humanas se convierte en el coro de múltiples narrativas particulares. Por consiguiente, la concepción de la subjetividad múltiple y fragmentada toma lugar del discurso acerca de la identidad sólida y coherente. No obstante, esta descentralización y deconstrucción del individuo no tiene connotaciones negativas, sino que se presenta en términos de flexibilidad, diversidad, expansión y renovación (Pacheco Acuña, 2009).

Cabe destacar que el pensamiento feminista, sobre todo en el marco de la denominada "segunda ola», insistía en que la esencia del ser, entendida como algo que debería descubrirse y preservarse a lo largo de la existencia del individuo, era un mito. Sus teóricos y teóricas señalaban que la subjetividad y el género son constructos culturales, a los cuales la sociedad atribuye determinadas características dependiendo del contexto. En este sentido, Rosi Braidotti, por ejemplo,

defendía un modelo de subjetividad plural, entendido como el desarrollo de «un nuevo nomadismo». Una noción de identidad múltiple y plural que se construye ficcionalmente, a partir de estrategias narrativas y existenciales. Multiplicidad de significados y formas de darse la identidad que coinciden con la imposibilidad de la visión unidireccional del mundo, que forma parte de la conciencia que sabe de la inutilidad de las manifestaciones de certidumbres inequívocas (Martínez-Collado Martínez y Navarrete Tudela, 2011, p. 17).

A modo de reflexión sobre estos planteamientos surgieron las ideas que aludían a la fragmentación, la hibridación y la pluralización del ser, como el concepto de ciborg con sus partes multifuncionales, lanzado por Donna Haraway, o «la imagen de "la nueva mestiza" formulada por Gloria Anzaldúa" (Pacheco Acuña, 2009, p. 357). Se trataba de los experimentos artísticos que revelaban la necesidad de adaptarse a las incertidumbres del mundo cambiante y la posibilidad de hacerlo desde la posición subversiva de la Otredad femenina. 
A su vez, la temática de la denuncia social del feminismo se expandió para abarcar los problemas de los Otros, comprendidos como cualquier colectivo marginado, oprimidos debido a su diferencia a lo normativo, a lo establecido, a lo dominante. Según Martínez-Collado Martínez y Navarrete Tudela (2011), esto se debía en parte a la convergencia de las preocupaciones entre los movimientos activistas por los derechos de la mujer y de las minorías y el reconocimiento de las aportaciones teóricas y artísticas de las feministas que operaban más allá del ámbito occidental. Esta tendencia representa el reflejo del pensamiento postcolonial que «integra la obligación de reconstruir desde lo popular, lo local, lo subalterno... interpretaciones culturales que han sido obligadas a permanecer en los márgenes de las lógicas dominantes» (Martínez Martin, 2016, p. 136). Asimismo, estos planteamientos se vinculan a la teoría queer y las tendencias feministas de corte antihumanista, desarrolladas bajo la influencia de las ideas de Michel Foucault, Jacques Derrida, Louis Althusser y Jacques Lacan (Pacheco Acuña, 2009). Ellas pretenden visibilizar la diferencia como parte inherente a nuestra sociedad actual y romper el imaginario colectivo que en gran medida se basa en las categorías dicotómicas para interpretar y representar la realidad.

Para lograr estos objetivos, era y es necesario establecer los mecanismos de la aproximación dialógica a la diferencia y desarticular aquellos que contribuyen a normalizar las perspectivas estereotipadas: «la educación, los medios de comunicación, la socialización familiar, la cultura, las tradiciones o las religiones" (Martínez Martin, 2016, p. 130). En cuanto a las representaciones de lo real o lo verdadero, resultaba imperante revelar que se trataba de una "verdad" construida en connivencia con ciertos intereses de poder y, por tanto, susceptible de la revisión (López Fernández, 1991). En este sentido, el activismo feminista desde sus inicios apostó por los medios audiovisuales, haciendo hincapié en su dimensión documental. Esto se reflejó, por ejemplo, en múltiples obras cercanas al cinema verité que denunciaban las injusticias sociales vinculadas a la discriminación por razón de género.

El formato videográfico se convirtió en uno de los predilectos en la lucha por los derechos de la mujer por varias razones. En primer lugar, no estaba tan influido por la tradición masculina, como la pintura y la escultura, lo que dejaba a las artistas mujeres cierta libertad para trazar el camino como las pioneras en estas prácticas y cobrar visibilidad y reconocimiento en el panorama artístico. Subrayando el carácter militante de los discursos audiovisuales feministas, Shigeko Kubota postulaba el vídeo como "la venganza de la vagina" (citado en Martínez-Collado Martínez y Navarrete Tudela, 2011, p. 13). En segundo lugar, la narrativa videográfica, así como los nuevos formatos digitales, brindaban y siguen brindando múltiples posibilidades para reflexionar sobre la temática del género y la identidad, visibilizar los mecanismos de su construcción a nivel sociocultural y las transformaciones que sufren estas nociones en el mundo contemporáneo. Surgieron las representaciones fragmentadas, con las alusiones a la deconstrucción del ser, su nomadismo perpetuo y pobladas de las criaturas plurales o híbridas que huían de la posibilidad de clasificación alguna, todo para poner en entredicho el constructo identitario. Estos discursos subversivos frecuentemente se formulaban desde el territorio simbólico de la Otredad femenina: lo doméstico, lo afectivo, lo privado, lo autobiográfico, por lo que se produjo un notable giro en el ámbito artístico hacia las historias y las voces particulares. Asimismo, el arte feminista exploraba el potencial pedagógico y propagandístico del vídeo, capaz de incidir directamente en el imaginario colectivo al utilizar los mecanismos de influencia en las masas similares a los que empleaban los medios de comunicación. Como ejemplo de 
esta fórmula creativa podemos destacar las obras de Ursula Biemann que representan un acopio del material de diversa índole que conforma una narrativa fragmentada y no lineal, acorde a la experiencia del mundo contemporáneo. Estos relatos aúnan múltiples voces particulares que versan sobre las problemáticas socioculturales y políticas. Otro modelo expresivo que emplean los y las artistas para despertar las conciencias ciudadanas frente a la discriminación de las minorías consiste en revelar la injusticia que acarrean los esquemas cognitivos dicotómicos. Las prácticas que se inscriben en este paradigma pretenden abrir la ventana hacia la realidad del Otro, median para presentar las diferencias no como un peligro, sino como fuente de enriquecimiento mutuo. Nos atrevemos a suponer que los proyectos documentales 'Art of Being Youself', 'The Word' y 'Vidimo-Nevidimo' de Kseniia Khrabrykh aúnan los dos modelos presentados. Para discernir los recursos expresivos que utiliza la artista para este fin analizaremos estas obras en el siguiente apartado.

\section{Resultados}

\subsection{Sobre la artista. Contextualización de su producción artística}

Kseniia Khrabrykh (1985) es una artista rusa interdisciplinar afincada en San Petersburgo. En su obra artística ella frecuentemente combina las narrativas audiovisuales con los elementos escultóricos y relacionales (Khrabrykh, s.f.). Así, entre sus últimas creaciones destacan varios documentales interactivos e instalaciones multimedia que involucran al público en la construcción del mensaje expresivo en constante evolución. La artista emplea este recurso con el fin de lograr mayor conexión entre los espectadores y su propuesta creativa, y, para ello, deja a la audiencia la libertad para interpretar el discurso y contribuir a su transformación. De esta manera, Khrabrykh trata de romper con la rigidez y rotundidad de los relatos documentales tradicionales, cuyo contenido suele tener pretensiones de generar una verdad absoluta. En realidad, es la forma idónea de aproximarse a la temática que atraviesa toda la producción artística de Khrabrykh hasta la fecha - la Otredad y la problemática vinculada a la falta de aceptación y tolerancia hacia la diferencia, sobre todo en lo que se refiere a la identidad de género.

Cabe señalar que la artista participa con sus trabajos en la actividad de Coming out (Vihod), una organización activista en defensa de los derechos del colectivo LGBT en San Petersburgo (Pohlers y Nikulicheva, 2013). Para contextualizar su obra es importante mencionar que en 2013 en Rusia fue adoptada la ley federal (Federalnyi zakon 135-FZ, 2013), que impone sanciones por la propaganda de las relaciones sexuales "no tradicionales» dirigida a los menores de edad. En el año 2017, Tribunal Europeo de Derechos Humanos resaltó que la formulación vaga de algunos aspectos de dicha legislación permite diversas interpretaciones y, por tanto, posibilita en cierta medida la discriminación de las personas cuya orientación sexual no se encuadra en los marcos «normativos» (European Court of Human Rights, 2017).

El deseo de visibilizar el alcance del problema de intolerancia hacia la diferencia en su país y proponer alguna solución, determina el discurso artístico de Khrabrykh. Así, en sus últimas obras de corte documentalista se refleja el miedo, el rechazo y la violencia hacia las personas que representan «lo extranjero» en el sentido más amplio de la palabra, tal y como la emplea Julia Kristeva. Se trata de un intento de abrir la 
ventana hacia la realidad del Otro, revelar los peligros del pensamiento dicotómico, y ofrecer la clave para superar sus limitaciones.

Es importante mencionar que Khrabrykh es la fundadora y la coordinadora el proyecto Taller del arte interactivo, con el cual trata de promover las prácticas artísticas interactivas en Rusia. Con este fin la página web de esta iniciativa (https://i-a-w.org/) incorpora los materiales visuales y bibliográficos sobre el tema y, asimismo, recoge la descripción detallada de todos los proyectos dirigidos por la artista-documentalista y sus colaboradores.

\subsection{ANÁlisis DE LAS OBRAS AUDIOVISUALES}

\subsection{1. 'Art of Being Yourself' ('Iskusstvo bit soboy')}

La primera obra de Kseniia Khrabrykh que nos proponemos analizar es el documental interactivo 'Art of Being Yourself' (2012). Su historia comenzó en el año 2011, cuando la organización Coming Out (Vihod) buscaba la manera de documentar el festival anual de la cultura queer en San Petersburgo (QUEERFEST 2012). La artista aceptó el reto y así nació la idea del proyecto, parte de cuyos resultados se puede ver en la página web del Taller del Arte Interactivo. Ahí se expone el prototipo del webdoc, que permite vislumbrar el relato multidimensional creado por Khrabrykh y las opciones de interacción disponibles para el usuario.

'Art of Being Yourself' aúna los datos recogidos por la artista en el curso de su investigación en torno a las problemáticas a las que se enfrenta el colectivo LGBT de San Petersburgo al principio del siglo XXI. El interfaz en formato de un mapa infográfico da oportunidad de navegar por la información recopilada en la base de datos subyacente, que incluye los documentos textuales y fotográficos, los artículos de prensa, las entrevistas grabadas en vídeo y otro tipo de testimonios vinculados a los procesos sociales que la autora pretende retratar. De esta manera, la audiencia puede explorar la compleja estructura de la narrativa no lineal, cuyas únicas guías se visualizan a modo de relaciones establecidas entre los distintos contenidos. El mapa cambia de aspecto dependiendo de las decisiones de navegación o "lectura" tomadas por el espectador. Este planteamiento permite analizar gran cantidad de datos de manera intuitiva y visual, conocer los hechos más destacables, adentrarse en los detalles de lo ocurrido y estudiar los vínculos conceptuales entre los distintos formatos del registro documental ("Taller del Arte Interactivo", s.f.). De este modo, Khrabrykh explora el potencial de la narrativa interactiva, no lineal y transmedia como vehículo para comprender los complejos fenómenos sociales. Su obra no impone ninguna verdad absoluta, sino ofrece al público la libertad de construir el relato y descubrir por sí mismo la naturaleza de los problemas expuestos. Asimismo, es importante señalar que el proyecto conforma un sistema vivo en constante desarrollo, gracias a las posibles contribuciones de los usuarios registrados.

Por consiguiente, en 'Art of Being Yourself' dos principales vías posibilitan la apertura hacia el contacto con el Otro: el contenido abierto de la obra, capaz de absorber las múltiples perspectivas aportadas por el público, y la estructura flexible de la narrativa que permite un acercamiento progresivo hacia una realidad ajena en reconstrucción perpetua. En este sentido, el proyecto se enmarca en lo que Sandra Gaudenzi (2013) denomina "Living Documentary", "an entity that has its organization, that is more or less open to change, that can affect the identity of the systems that 
are related to it and that can eventually stop functioning/existing [una entidad que tiene su organización, que está más o menos abierta al cambio, que puede afectar la identidad de los sistemas relacionados con ella y que eventualmente puede dejar de funcionar / existir (traducción de la autora)]» (p.243). Gaudenzi (2013) afirma que este tipo de obras establecen un intercambio bidireccional con su contexto, lo que provoca las transformaciones en ambas partes. De esta manera, semejantes proyectos inciden en el cambio social al mostrar un compromiso firme con su entorno sociocultural y político. En el caso que nos ocupa, el discurso artístico desafía los esquemas de pensamiento hegemónico que promueven la discriminación en referencia a la identidad de género. No hay mejor forma de romper con las concepciones dicotómicas rígidas que ofrecer una alternativa para la construcción de conocimiento, más flexible y sensible a los distintos matices de la realidad. Así, por ejemplo, el mapa de navegación por la narrativa de la obra de Khrabrykh (2012) refleja las relaciones complejas que existen entre las unidades de información. Como consecuencia, es evidente que las múltiples rutas pueden ofrecer diferentes combinaciones de datos, susceptibles de interpretación por el usuario. No existe una única historia que contar, como no existe la forma "correcta» de hacerlo. Al igual que no podemos establecer una guía para la vida o construir nuestra identidad de una vez por todas. Por tanto, «el arte de ser uno mismo" consiste en aprender a estar en un devenir permanente, aceptar la complejidad de nuestro Yo con todas sus contradicciones e incoherencias y reconocer al Otro como fuente de enriquecimiento mutuo. Estas ideas encuentran su fundamento en el pensamiento feminista postcolonial y la teoría queer.

\subsection{2. 'The word' ('Slovo')}

Otra obra de Khrabrykh que nos gustaría analizar en el marco de nuestro estudio es el proyecto 'The Word' ('Slovo'), que salió en 2017 bajo el patrocinio de LGBT-Red (San Petersburgo). Este documental interactivo alude al lenguaje como el origen de la violencia. Se compone de dos líneas narrativas paralelas, entre las cuales el espectador puede desplazarse pulsando la tecla Espacio. En la primera secuencia podemos ver a los nueve protagonistas del filme, hombres y mujeres. Son percibidos por la sociedad como diferentes por distintos motivos: su aspecto físico que no responde a los cánones de belleza actuales, su condición social marginal, su procedencia, su edad, su sexualidad, su estado de salud, etc. Durante seis minutos y medio ellos se dirigen al espectador verbalizando las palabras ofensivas que otras personas dijeron en algún momento a los individuos de condición similar a la suya. La recopilación de estos insultos, publicados por los usuarios en las redes sociales, los foros, los blogs, etc. o pronunciados en los medios de comunicación por los personajes públicos, constituyó la primera fase del proyecto 'The Word'.

Nos parece importante destacar las decisiones de la artista en relación a la construcción visual del discurso del documental y la introducción de la posibilidad de interactividad como parte de la experiencia del público. En la primera secuencia los personajes aparecen en primer plano y tratan de mantener el contacto visual con el espectador imaginario mientras pronuncian las palabras hirientes. Sus ojos reflejan el daño que causan estas expresiones de desprecio. A su vez, por si el efecto de este intercambio no fuera lo suficientemente impactante, la artista añade un componente interactivo a su narrativa. El usuario puede pulsar la barra espaciadora para ver cómo 
la agresión verbal se convierte en la física en las escenas de violencia hacia los colectivos marginados. De esta manera, a través de la segunda línea narrativa se revela que entre la palabra y la acción no hay tanta distancia como creemos. El propio insulto ya es hiriente y capaz de destruir poco a poco a su objetivo desde dentro. Además, aquellos quienes lanzan la ofensa también quedan afectados. Su rechazo hacia todo lo que sale de la norma, todo lo que encarna la Otredad se debe al pensamiento arraigado de que la diversidad representa peligro y debe ser aniquilada. No se dan cuenta de que su acto puede cambiar de dirección y el juez se convertirá en víctima, ya que la definición de lo Otro es susceptible de ser cambiada en cualquier momento («aller del Arte Interactivo", s.f.).

Otro aspecto interesante de esta obra que nos gustaría resaltar es su formato híbrido. A pesar de que se presenta como un filme documental, los protagonistas no prestan su testimonio, sino que, en cierta medida, interpretan un papel, verbalizan las ofensas y así se ponen en el rol del agresor. Por otro lado, en algún momento de su vida cada uno de ellos sintió lo que significa ser insultado y humillado por ser diferente. Como consecuencia, se identifican con la situación, pero empatizan con la parte afectada, son el verdugo y la víctima a la vez y las emociones que expresan sus caras son reales. En este sentido, cabe preguntarse dónde podríamos situar la frontera entre el documental y la ficción y cuál es la relación de cada uno de estos géneros con la realidad.

La narrativa documental del proyecto 'The Word' incorpora dos principales recursos para aludir a la dicotomía "normal-diferente». En primer lugar, los protagonistas del audiovisual manifiestan su sufrimiento por el rechazo hacia su condición que no encaja en la definición de lo común. El espectador escucha de sus labios los insultos y, de esta manera, se intercambia los papeles con el Otro. De repente, el público es el objeto de las palabras despectivas, lo que produce una sensación del extrañamiento. No obstante, la falta de la agresión en los ojos del oponente al pronunciar las ofensas evita que el espectador se sienta involucrado en una confrontación. Esta dosis de descentralización pretende subvertir los esquemas de estereotipos arraigados y conforma el primer paso hacia la ruptura con la estructuración mental dicotómica. En segundo lugar, la posibilidad de interactuar con el material documental, pasar de visualizar la violencia verbal a presenciar las escenas de la agresión física, permite concienciar al público de la poca distancia que existe entre una frase que expresa el rechazo y el ataque a la integridad corporal. Sin embargo, la primera puede llegar a ser socialmente aceptada como la expresión de una opinión y el segundo está penado por la ley. Esto revela el peligro que supone la conceptualización de las categorías existenciales desde los preceptos antagónicos y la necesidad de tener en cuenta las nociones híbridas en el cuadro de la realidad social.

De nuevo observamos que el discurso que formula Khrabrykh (2017) en su obra muestra un vínculo evidente con la teoría queer y el pensamiento feminista postcolonial. La Otredad aquí ya no está representada únicamente por el colectivo LGBT, como en 'Art of Being Yourself', sino que aparece como algo inherente a la sociedad actual. La discriminación toca de cerca a los que sufren alguna enfermedad, a los que ya no son jóvenes, a los que no tienen aspecto atractivo según los estándares del momento, etc. De repente, nos damos cuenta de que cualquiera puede pasar a formar parte de "los despreciados», que la frontera entre "lo normal» y «lo diferente» es efímera. Y surge la pregunta inevitable: ¿quién define este límite? Y aún más importante: ¿podemos hacer algo para cambiar la situación? 


\subsection{3. 'Vidimo-Nevidimo'}

Finalmente, nos gustaría hablar de la creación más reciente de Kseniia Khrabrykh, el documental 'Vidimo-Nevidimo' (2018). La obra fue presentada 25 de noviembre de 2018, el día internacional de la lucha por la eliminación de la violencia en contra de las mujeres. La artista describe el proyecto como «el experimento social sobre el tema de la violencia de género» (Taller del Arte Interactivo», s.f.) y puntualiza que el uso de la realidad virtual conforma el aspecto fundamental de la construcción de su discurso.

Se trata de una pieza videográfica con narrativa lineal que dura 33 minutos y 23 segundos. Se compone de las entrevistas realizadas a cinco mujeres y cuatro hombres, a los cuales se les propuso durante el rodaje observar a través de las VR-gafas varias escenas violentas representadas por los actores. Entre las situaciones que presenciaban de esta manera los participantes se encontraban: el despido de un hombre debido a su forma de vestir y comportarse, el acoso y la agresión sexual hacia una joven en una fiesta, una mujer abordada por un hombre ebrio en una parada de autobús, etc. Los implicados veían toda la situación desde la perspectiva de la víctima y, de esta forma, tenían la oportunidad de sentirse más identificados con sus reacciones y emociones. Su respuesta fue documentada tanto durante la visualización del contenido, como en una entrevista realizada inmediatamente después de ella.

Algunos de los protagonistas se quedaron conmocionados por lo que habían visto y pidieron un momento para poder tranquilizarse, otros fueron más contenidos e, incluso, hubo quienes cayeron en la negación de la gravedad de los hechos presenciados. Tres de cinco escenas mostradas reflejaban la agresión, tanto verbal, como física, dirigida a una mujer. Como consecuencia, a las participantes femeninas les fue más fácil empatizar con el personaje que sufría la ofensa. Aparte de ello, algunas de ellas declararon haber pasado por la experiencia semejante. Lo contrario pasó con algunos de los hombres entrevistados. Uno de ellos criticó el hecho de que casi todos los vídeos presentaban en el papel del atacante a un hombre y declaró que esto le hizo sentirse incómodo, discriminado y poco identificado con las situaciones que presenció. Es más, en varias escenas de violencia la artista añadió mayor tensión entre los polos "Yo-Otro» al profundizar la alteridad en el aspecto de la orientación sexual. Así, en uno de los casos la violencia ejercida contra la mujer homosexual es mayor y es justificada por sus agresores como la necesidad de "enderezarla». En el otro vídeo el hombre es humillado por sus colegas y despedido de su trabajo debido a su sexualidad "periférica» (Fonseca Hernández y Quintero Soto, 2009). En este sentido, las actitudes violentas son la expresión del pensamiento dicotómico que confronta la norma y la diferencia.

Cabe destacar que en el documental 'Vidimo-Nevidimo' Khrabrykh confiere gran protagonismo a la composición del plano y el encuadre como recurso expresivo. Así, en la parte introductoria, cuando los participantes se estaban presentando, la artista se decantó por un plano general de los entrevistados que permitía recibir una primera impresión de ellos por su físico y vestimenta. Era un momento formal, donde la tensión derivaba de la incertidumbre y la expectación de los presentes. En las siguientes escenas los entrevistados llevaban gafas VR y reaccionaban de manera gestual a los acontecimientos observados. En ellas la característica compositiva mencionada se conservaba, debido a la importancia de captar el lenguaje corporal de los involucrados. Por último, llegó el momento de compartir sus impresiones y fue cuando la cámara se acercó en varias ocasiones para registrar todas las emociones reflejadas en los rostros de los participantes. 
Esta obra de Khrabrykh (2018) es quizás la que más claramente hace alusión a la Otredad femenina basada en la dicotomía «hombre-mujer». Las cuestiones que atañen a la problemática de la violencia de género atraviesan toda la pieza, desde los materiales audiovisuales ofrecidos a los participantes para su visionado, hasta la intervención de los protagonistas al ver las escenas y comentar lo ocurrido. Asimismo, la pieza refleja la dualidad "agresor-víctima» y obliga a los protagonistas a ponerse en la piel de la segunda. Este ejercicio de empatía produce gran impacto emocional en todos los involucrados, aunque no siempre genera una respuesta positiva en cuanto al contenido observado. Algunos muestran reacciones defensivas, intentan descalificar el discurso presentado, buscar fallos en su planteamiento, pero esta resistencia forma parte del proceso de cambio. Sin oposición no hay diálogo, sin conflicto no hay transformación y este hecho encuentra su reflejo en la obra.

Otra dicotomía que cuestiona Khrabrykh (2018) es la dualidad «real-virtual». La frontera entre ambas categorías en los últimos años tiende a desaparecer, algo que observamos claramente en 'Vidimo-Nevidimo'. Sus protagonistas se enfrentaron a una ventana hacia la realidad del Otro, la realidad que nosotros no podemos ver y la percibimos solamente a través de sus reacciones, sus movimientos, sus réplicas. Observamos su encuentro con la Otredad y su capacidad de empatizar con las circunstancias ajenas y lo hacemos sin sentir el rechazo involuntario. Este desplazamiento de la perspectiva en la presentación de la problemática documentada incita a la reflexión sobre la violencia de género de manera mucho más efectiva que una imposición de un punto de vista. En este caso, la dicotomía no se revela a través de los recursos interactivos, sino se vislumbra en el juego perceptivo de un mensaje abierto a la interpretación.

Por último, podríamos decir que, de las tres piezas analizadas, el proyecto 'VidimoNevidimo' de Kseniia Khrabrykh es el que manifiesta mayor afinidad con el discurso feminista. Al hilo de ello, cabe señalar que el título de la obra se podría traducir como "visto-no visto» o "muchísimo». La primera interpretación hace referencia al hecho de que, aunque la violencia de género ha dejado de ser un tema tabú en las sociedades occidentales, todavía hay muchos aspectos de ella que permanecen ocultas o no encuentran solución. La segunda, a su vez, alude a la proliferación de las actitudes intolerantes en la actualidad. Para poner freno a esta situación, aparte del documental con estructura narrativa lineal disponible en la página web del Taller de Arte Interactivo, en el marco de la campaña para luchar en contra de la violencia de género fue creado el canal homónimo en Youtube (Vidimo-Nevidimo, 2018), donde a disposición del espectador se pone el material 3D que vieron los participantes del proyecto.

En definitiva, los discursos artísticos de las tres obras analizadas tratan de ofrecer una alternativa al modo de pensar alienante, dictado por el miedo hacia la diferencia. Proponen un espacio simbólico de encuentro con la Otredad, a través del cual las personas pueden acercarse a lo desconocido, ponerse en el lugar del oponente, descubrir su historia y establecer los vínculos entre esta y el relato propio. En este sentido, conforman una vía segura donde uno puede despojarse poco a poco de los prejuicios y trazar el camino hacia una mentalidad abierta fuera de las imposiciones del pensamiento dicotómico. 


\section{Conclusiones}

El mundo contemporáneo cambiante impone la diversidad como parte inherente a las sociedades actuales. No obstante, los esquemas cognitivos que estructuran nuestra interpretación de la realidad no resultan tan fáciles de transformar. Así, seguimos definiendo a nuestro propio ser en contraposición a todo lo que nos es ajeno y desconocido y cerramos de esta manera los caminos hacia el intercambio con el Otro con todos los beneficios que puede entrañar, para evitar sus peligros, muchas veces imaginarios. Para romper con esta dinámica negativa necesitamos abrir una ventana hacia la Otredad y aceptarla como partícipe fundamental de nuestro propio proceso de construcción identitaria. En este sentido, el arte ofrece una posible solución.

En el presente estudio presentamos el análisis interpretativo de las producciones audiovisuales documentales 'The Word', 'Vidimo-Nevidimo' y 'Art of Being Yourself' de Kseniia Khrabrykh, una artista emergente rusa, para establecer qué recursos artísticos se emplean en ellas con el fin de evocar la alteridad y revelar los peligros que entrañan las dicotomías existenciales impuestas por el pensamiento dominante.

Así, entre las herramientas expresivas, utilizadas por la artista para cumplir con el objetivo propuesto, destacan: la estructura narrativa no lineal, fragmentada y con elementos de interactividad; el sistema del contenido flexible y abierto a las aportaciones del público; la permuta de roles entre el Yo y el Otro y el desplazamiento o la mediación entre el espectador y aquello que él percibe como alteridad.

Así, por ejemplo, las múltiples lecturas del relato multidimensional de 'Art of Being Yourself' posibilitan la construcción del conocimiento por descubrimiento y evitan la imposición de una verdad absoluta. A su vez, en esta obra y en 'The Word' los componentes interactivos trasmiten un mensaje conceptual: en la primera, la artista sugiere que tanto la historia, como nuestra identidad son entes cambiantes y, en la segunda, el salto entre dos líneas narrativas indica que la distancia entre la palabra injusta y la agresión es mínima.

Aparte de la estructuración poco ortodoxa del relato, la inestabilidad y la fragmentación del discurso de 'Art of Being Yourself' aumenta por las contribuciones que puede hacer la audiencia a su contenido. Esta apertura hacia lo inesperado no sólo impulsa la evolución de la obra, sino también constituye un nuevo espacio para el diálogo e intercambio social.

En cuanto a la confusión entre el Yo y el Otro, en 'Vidimo-Nevidimo' y 'The Word' este elemento expresivo está dirigido a producir el extrañamiento en el espectador y le permite empatizar de manera más profunda con la problemática expuesta. Esto ayuda al público a cuestionar su cognición dicotómica a través de la convergencia simbólica entre su realidad y las experiencias de la Otredad.

Por último, las tres piezas analizadas se presentan en calidad de mediadores entre los mundos opuestos, aunque evaden la imposición de una opinión determinada y, de esta manera, dejan libertad al espectador para tomar una posición personal ante el tema en cuestión, fuera de juicios de valor y estereotipos. En definitiva, las obras estudiadas en nuestro ensayo incorporan distintas combinaciones de los recursos artísticos mencionados, dependiendo de la temática y el enfoque elegido por la artista en cada caso.

El hilo conductor entre las tres piezas es el concepto de la identidad, entendido como ente fragmentado y plural en constante transformación. Asimismo, en ellas la artista cuestiona la rotundidad de la oposición entre lo real y lo virtual, el hombre y la 
mujer, lo heterosexual y lo homosexual, lo normal y lo diferente y evoca la alteridad con el fin de romper con las dicotomías existenciales impuestas por el pensamiento dominante. Con su discurso subversivo, Khrabrykh pretende impulsar la mentalidad más flexible dispuesta a acoger la Otredad como parte de cada uno de nosotros. En este sentido, muchas de sus ideas encuentran su fundamento en la teoría queer y los feminismos postcoloniales, aunque ella no manifiesta claramente sus preferencias por estos últimos.

En sus creaciones la artista utiliza el formato audiovisual de corte documental como vía de inmersión en una realidad ajena con el fin de favorecer las actitudes tolerantes hacia la diversidad. Sus narrativas incluyen componentes interactivos que no solo ayudan al espectador a conectar mejor con la problemática expuesta, sino también lo implican en la construcción del relato. Este aumento de control del público sobre la historia revela la importancia que ella confiere a la parte interpretativa de la experiencia artística. La libertad que se otorga a los espectadores conforma otro intento de su descentralización con el fin de destruir las edificaciones simbólicas rígidas, derivadas de la oposición "verdad-mentira» y abrir las posibilidades para mayor complejidad perceptiva. De esta manera, su obra pone en valor los novedosos formatos de audiovisual documental como posibles portadores de las estructuras cognitivas alternativas a las dicotómicas.

\section{Bibliografía}

Arfuch, L. (2002). El espacio biográfico. Dilemas de la subjetividad contemporánea. Buenos Aires: FCE.

Cano, J. E. (2016). La «otredad» femenina: construcción cultural patriarcal y resistencias feministas Asparkía. Investigació feminista, O(29), 49-62. Recuperado de http://www.e-revistes.uji. es/index.php/asparkia/article/view/2341

De Beauvoir, S. (2013). El segundo sexo. Buenos Aires: Debolsillo.

European Court of Human Rights (Third Section). (2017). Case of Bayev and Others v. Russia. Judgment. Counsil of Europe: Strasbourg. Recuperado de https://hudoc.echr.coe.int/eng\#\{\% 22itemid\%22:[\%22001-174422\%22]\}

Federalnyi zakon $\mathrm{N}^{\circ}$ 135-FZ. (2013). O vnesenii izmeneniy v stat'yu 5 Federal'nogo zakona "O zashchite detey ot informatsii, prichinyayushchey vred ikh zdorov'yu i razvitiyu'i otdel'nye zakonodatel'nye akty Rossiyskoy Federatsii $v$ tselyakh zashchity detey ot informatsii, propagandiruyushchey otritsanie traditsionnykh semeynykh tsennostey [On the Change to the Federal Law on Protection of Children from Harmful Information and Other Legislative Acts] from 29.06. 2013. Russian Federation.

Fonseca Hernández, C. y Quintero Soto, M. L. (2009). La Teoría Queer: la de-construcción de las sexualidades periféricas. Sociológica (México), 24(69), 43-60. Recuperado de http:// www.scielo.org.mx/scielo.php?script=sci_abstract\&pid=S0187-01732009000100003\&lng $=$ es\&nrm=iso\&tlng=es

Gaudenzi, S. (2013). The Living Documentary: from representing reality to co-creating reality in digital interactive documentary (Tesis doctoral sin publicar). Goldsmiths, University of London, London. Recuperado de http://research.gold.ac.uk/7997/

Hall, S. (2003). ¿Quién necesita 'identidad'? En S. Hall y P. du Gay. (2003). Cuestiones de identidad cultural. (pp. 13-39). Buenos Aires: Amorrortu.

Khrabrykh, K. (s.f.). [Página web de la artista]. Disponible en http://khrabrykh.com/

Khrabrykh, K. (directora) (2012). The Art of Being Yourself [Iskusstvo bit soboy]. [Documental interactivo]. Disponible en https://i-a-w.org/project/vidimo-nevidimo 
Khrabrykh, K. (directora) (2017). The Word [Slovo]. [Documental interactivo]. San Petersburgo: Taller de Arte Interactivo y Russian LGBT-red. Disponible en http://slovo-film.com/

Khrabrykh, K. (directora) (2018). Vidimo-Nevidimo [Documental]. San Petersburgo: Oxfam y Taller de Arte Interactivo. Disponible en https://i-a-w.org/project/vidimo-nevidimo

Kristeva, J. (1991). Extranjeros para nosotros mismos. Barcelona: Plaza \& Janes.

López Fernández, M. (1991). Arte, feminismo y posmodernidad: apuntes de lo que viene. Arte, Individuo y Sociedad, (4), 103-109.

Martínez-Collado Martínez, A. y Navarrete Tudela, A. (2011). Mujeres e (industria) audiovisual hoy: Involución, experimentación y nuevos modelos narrativos. TESI. Teoría de la Educación. Educación y cultura en la Sociedad de la Información, 12(1), 8-23. Recuperado de http://campus.usal.es/ revistas_trabajo/index.php/revistatesi/article/view/8271

Martínez Martin, I. (2016). Construcción de una pedagogía feminista para una ciudadanía transformadora y contrahegemónica. Foro de Educación, 14(20), 129-151. Recuperado de https:// doi.org/10.14516/fde.2016.014.020.008

Olsen, F. (2009). El sexo del derecho. En Ávila Santamaría, R., Salgado, J. y Valladares, L. (Comps.). El género en el derecho. Ensayos críticos. Ecuador: Ministerio de Justicia y Derechos Humanos.

Pacheco Acuña, G. (2009). De la otredad a la identidad: perspectivas de teoría feminista de fines del siglo XX. Revista de Lenguas Modernas, (10), 353-359.

Pohlers, A.-K. y Nikulicheva, E. (2013). The art of Being Yourself (18+) [Iskusstvo bit samim soboi (18+)]. To4ka-Treff, febrero 2013. Recuperado de http://www.goethe.de/ins/ru/lp/prj/ $\mathrm{drj} / \mathrm{top} / \mathrm{min} / \mathrm{ru} 10437809 . \mathrm{htm}$

Taller del Arte Interactivo [Masterskaya Interactivnogo Iskusstva]. (s.f.). [Página web] Disponible en https://i-a-w.org/

Varela, N. (2005). Feminismo para principiantes. Barcelona: Ediciones B.

Vidimo-Nevidimo (2018). [Canal YouTube]. Disponible en https://www.youtube.com/channel/ UCiA3-5B6LiMzeaUNAFx0fSg/featured

Zavala, L. (2010). El análisis cinematográfico y su diversidad metodológica. Revista Casa del Tiempo, 4(30), 65-68. Recuperado de http://www.uam.mx/difusion/casadeltiempo/30_iv_ abr_2010/casa_del_tiempo_eIV_num30_65_69.pdf

\section{Agradecimientos}

El presente estudio ha sido realizado en el marco de la investigación para la tesis doctoral de Anna Borisova al amparo del contrato predoctoral del Plan Propio de la Universidad de Murcia. 
